\section{LA “CULTURA CONVERGENTE" Y LA FILOSOFÍA WEB 2.0 EN LA REFORMULACIÓN DE LA COMUNICACIÓN CIENTÍFICA EN LA ERA DEL CIBERPERIODISMO}

\author{
Carlos Elías \\ Dpto. de Periodismo y Comunicación Audiovisual \\ Universidad Carlos III de Madrid \\ carlos.elias@uc3m.es
}

\section{THE CONVERGENT CULTURE AND THE WEB 2.0 PHILOSOPHY IN THE REFORMULATION OF THE SCIENTIFIC COMMUNICATION DURING THE ERA OF CYBER-JOURNALISM}

ABSTRACT: Internet has modified in deep the traditional relationship between journalists and their sources. The communication among scientists and between scientific sources and society has changed as well. Nowadays journalists, scientists, bloggers or any curious person from anywhere can access without any problem to every scientific institution web sites. So the scientific source (e.g. NASA) could be considered as mass media itself; and because of that some scientists could produce science "designed" for feed the "media" they belong to. Science is ruled by the audience dictatorship as mass media do. In an international discipline such as science, the new cybernetic environment has changed the scientific communication more than ever. In this article, we analyze these changes according to the rules of a new paradigm called "convergence culture" and the developing Web 2.0 philosophy.

KEY WORDS: Scientific journalism, science and society, cyberjournalism, convergence culture.
RESUMEN: Internet ha modificado profundamente la relación que siempre ha existido entre el periodista y su fuente, la comunicación entre los propios científicos y entre la fuente científica y la sociedad. Ahora cualquier periodista, científico, blogger o curioso puede acceder sin problema a la web de la fuente cientifica. La propia fuente (por ejemplo, la NASA) se considera entonces un medio de comunicación de masas a todos los efectos. Debido a ello, muchos científicos comienzan a producir ciencia para alimentar a "su medio de comunicación". La ciencia acepta la dictadura de la audiencia. En una disciplina tan internacional como la ciencia, el nuevo entorno cibernético lo ha cambiado todo. En este artículo se analizan estos cambios bajo la perspectiva del nuevo paradigma de la "cultura convergente" y del desarrollo creciente de la filosofía Web 2.0.

PALABRAS CLAVE: Periodismo científico, ciencia y sociedad, ciberperiodismo, cultura convergente.

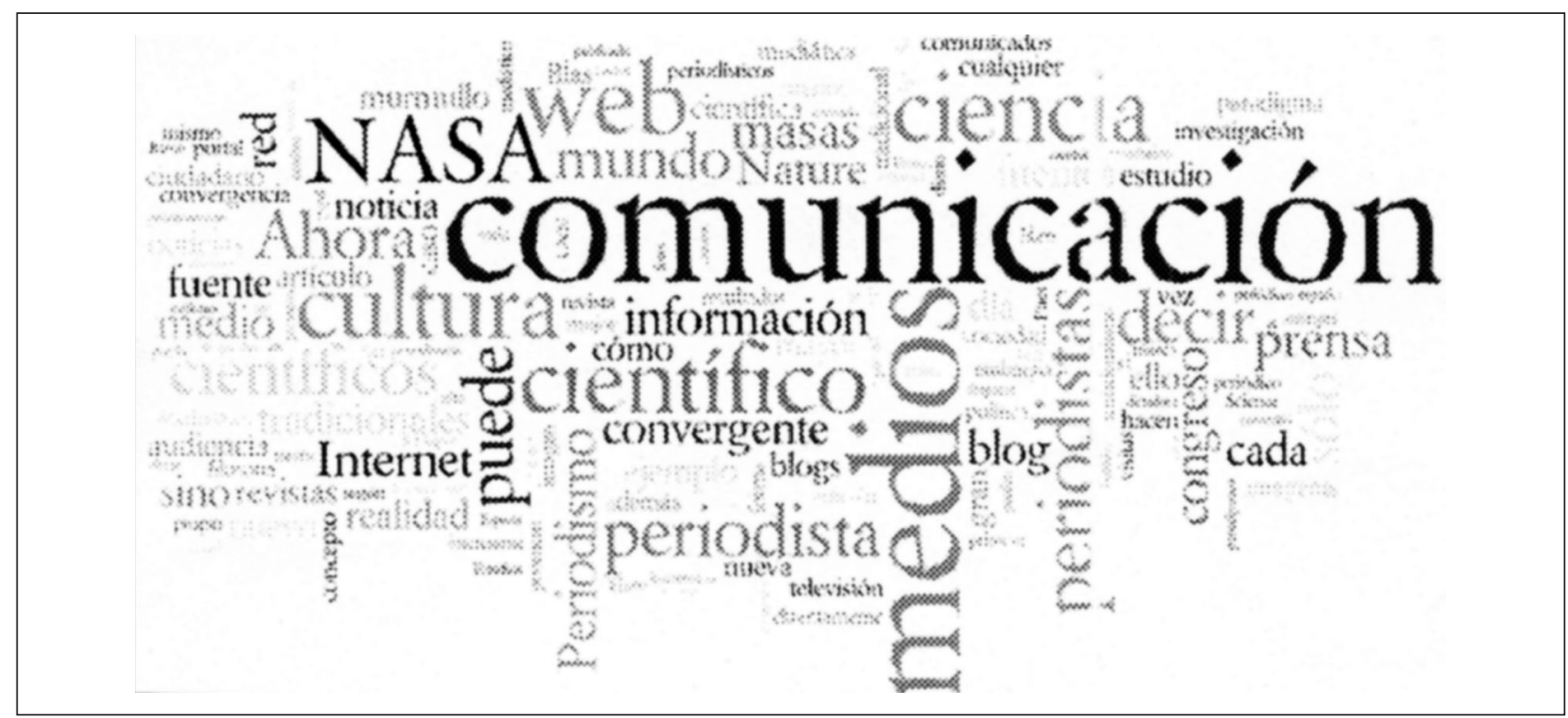




\section{INTRODUCCIÓN}

Internet ha modificado radicalmente el oficio periodistico. Hace unos años, nadie previó esta gran transformación aunque, quizá, una de las escasas excepciones fuera Alvin Toffler en su libro La tercera ola (Toffler, 1980). Por primera vez se hablaba de comunicación "varios a varios", de que la producción de los medios se iba "desmasificar" y de que, por tanto, nacía la comunicación mediática personalizada. No existiría ya el concepto comunicación de masas que tanto gustaba a los periodistas -por el

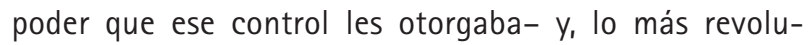
cionario del libro, el espectador podría intervenir en los periódicos que leería y en la televisión que vería. Cuando se publicó el libro, a principios de los ochenta, al menos en las facultades de comunicación se veía como una ciencia-ficción, similar a cuando los físicos hablan de viajes en el tiempo. Todavía a mediados y finales de los noventa (cuando yo era estudiante de Periodismo) se le daba más credibilidad a los aspectos sociológicos del libro (la desaparición de la familia tradicional, el aumento de la soledad, la "cultura sin hijos", o el nuevo trabajo infantil) que a sus especulaciones sobre cómo evolucionarían los medios de comunicación de masas. A principios de este siglo, cuando ya estaba plenamente operativa la hoy denominada web 1.0 se hablaba de "Periodismo e Internet: nuevo medio, vieja profesión" y se subrayaba que debían ser "los periodistas quienes introduzcan en la red los contenidos informativos de carácter periodístico, única forma de garantizar la calidad, objetividad, veracidad y credibilidad en la información (Canga Larequi, 2001: 33)". Por otro lado, se hacía hincapié en etiquetas de la etapa anterior como "el prestigio de la marca" y se señalaba que "la imagen de marca resulta determinante, en este momento, para garantizar la fiabilidad de la información que, si es buena en el papel, también lo será en la red (Edo, 2001: 59)".

Sin embargo, en 2005 el tratamiento cambia. En un análisis sobre los portales web de los periódicos gratuitos españoles se describe el portal del diario Qué y se destaca que "se presenta como un espacio de comunicación personal, ya que en su portada los mejores artículos son elaborados por los lectores. (...) La selección queda marcada por la dirección del diario que es quien decide qué artículo es más interesante y destaca el blog del día en la parte superior de la portada (Franco Álvarez, 2005: 181)".
Todavía estaba la selección de los blog en manos de la dirección del periódico. Es decir, los periodistas conservaban el poder jerarquizador de noticias (uno de los más importantes de la profesión), pero se vislumbra el cambio de que son los ciudadanos los que hacen la información. Comienza a hablarse de "periodismo ciudadano". Medios de comunicación españoles como Menéame.net elaboran ya sus portadas exclusivamente en función de la selección de los lectores. Es decir, no les hace falta el periodista tradicional.

¿Qué sucedió entre la visión de 2001 y la de 2005? Pues básicamente la irrupción generalizada de lo que se ha denominado filosofía Web 2.0, término propuesto en 2004 por Tim O'Reilly para describir a una segunda etapa en la historia la red basada en comunidades de usuarios, donde éstos interactúan a través de redes sociales, blogs, etc. Lo más importante de la Web 2.0, además del fácil acceso, es la posibilidad de modificar tanto el contenido como la estructura de los textos. También se puede poner material en línea y participar tanto personal como colectivamente. Es decir, la Web 2.0 permite a los ciudadanos convertirse en protagonistas relevantes del proceso informativo, algo antes destinado sólo a los periodistas. No es lo mismo consultar pasivamente la Enciclopedia Británica por la red (Web 1.0), que Wikipedia (Web 2.0) en la que todos podemos colaborar. Es cierto que, quizá, la cantante Madona pueda tener una entrada mayor que la de Aristóteles; pero en la nueva era, las jerarquías de los conocimientos se diluyen.

El periodismo 2.0 puede ser elaborado directamente por el ciudadano (aunque, obviamente, los periodistas también son ciudadanos) al margen de las grandes empresas mediáticas. Aparecen nuevos términos: ya no se habla de géneros periodísticos, sino de "narración transmediática" y nos referimos a los viejos entramados de empresas periodísticas como "hibridación corporativa"; el cada día más anticuado concepto de audiencias o, incluso, de opinión pública, se modifica en Web 2.0 con el de "inteligencia colectiva" (Pierre Lévi) o "multitudes inteligentes" (Howard Rheingold). Ya no hablamos de editores de los textos periodísticos (los antiguos jefes de sección o redactores jefes), sino de "lectura beta", un concepto en el que el propio lector puede reelaborar (editar) en la red el texto escrito por el periodista y volcarlo editado por él. 
El concepto de MMORPG (del inglés Massively Multiplayer Online Role-Playing Games); es decir, juego de rol en línea multijugador (un juego que reúne a miles de personas que interaccionan a través de avatares en un entorno de fantasía) ha dado paso a otro más sofisticado como el de "realidad alternativa", acuñado por Jane McGonigal. Esas realidades alternativas interaccionan con la "real".

Los periodistas tuvimos un shock cuando una de las agencias de noticias más importantes del mundo, Reuters, abrió en 2006 su propio avatar "oficina y su periodista" en Second Life (un espacio de realidad virtual). ¿Puede un periodista contar realidades alternativas? ¿Existe traspaso informativo de una realidad a otra? ¿Debe hacerlo el periodista? ¿Eso es periodismo? Preguntas complejas del nuevo ciberperiodismo. Cuando Gaspar Llamazares, el líder del partido español Izquierda Unida, decidió en 2007 dar un mitin en Second Life, lo relevante no fue lo que dijo, sino que ese mitin tuvo mucha mayor cobertura mediática en medios "reales" que cualquier otro que diera en la realidad "real". Llamazares emulaba a los políticos franceses Nicolás Sarkozy o Ségolène Royal. Desde mi punto de vista, Second Life no ha tenido la repercusión que se le atribuia (en especial los teóricos cibernéticos). En 2008 Reuters cerró su oficina. Pero demostró que el mundo no es lo que era. Estamos, por tanto, en un momento de incertidumbre en el que lo viejo parece que desaparece, pero no sabemos qué es lo que sustituye.

\section{UN NUEVO PARADIGMA: LA CULTURA CONVERGENTE}

Uno de los enfoque más atractivos que han aparecido en los últimos tiempos para intentar explicar lo que sucede en los medios de comunicación con la irrupción de Internet (sobre todo de la Web 2.0) es el denominado "paradigma de la cultura convergente", acuñado en 2006 por el profesor de Estudios Mediáticos del MIT Henry Jenkins. Esta "cultura convergente" sería la suma de tres subprocesos relacionados en distintos niveles con la filosofía Web 2.0: la convergencia mediática, la cultura participativa y la inteligencia colectiva.

La primera aproximación al fenómeno la describiremos con un "caso estudio" que está siendo muy analizado (Rosenzweig, 2003; Jenkins, 2006; Lozano, 2008). En oto- ño de 2001, tras los atentados del 11 de septiembre en Nueva York, Dino Ignacio, un anónimo estudiante filipinoamericano de secundaria diseñó un collage digital con Photoshop. Con toda su inocencia de chaval, juntaba la imagen de Bin Laden (considerado como autor intelectual del atentado en los medios de comunicación) con la del cascarrabias Blas, personaje de la serie infantil de distribución global Barrio Sésamo (iniciada en 1970 y que continúa en la actualidad). Colgó en su web personal una serie de imágenes tituladas "Blas es malo". En realidad, sólo era una broma, pero el blog fue pasando de un lado a otro, incrementando su posicionamiento en los motores de búsqueda. Blas (y su amigo Epi) son iconos globales de todos los occidentales nacidos desde mediados de los sesenta. Es decir, de la mayoría de los usuarios de Internet.

Ese pequeño éxito posiblemente fuera la causa de que un editor de Bangladesh encontrara y seleccionara el collage, cuando chequeó la red en busca de imágenes de Bin Laden para imprimirlas en carteles y camisetas antiamericanas que llevarian miles de manifestantes en Pakistán contrarios a la política de EEUU tras el 11S. En Pakistán puede verse un formato adaptado de Barrio Sésamo, pero en él no aparecen los personajes Epi y Blas. Las manifestaciones fueron recogidas por la CNN y transmitidas de manera global. Los representantes de Children's Televisión Workshop, creadores de la serie Barrio Sésamo, contemplaron escandalizados las imágenes en la que furiosos manifestantes portaban carteles con la fotografía de Bin Laden junto al muñeco Blas y amenazaron con emprender acciones legales. "Nos sentimos indignados por el deplorable y desagradable uso de nuestros personajes. Los responsables de ello deberían sentirse avergonzados. Estamos explorando todas las opciones legales para detener este abuso", dijeron sus abogados en los medios de comunicación. La CNN se defendió diciendo que ellos sólo emitian imágenes noticiosas de la realidad. Y esas manifestaciones con las imágenes de Blas con Bin Laden eran la realidad.

Inmediatamente se crearon numerosos foros de fans bromistas que relacionaban terroristas con personajes de $B a-$ rrio Sésamo. Pero, además, Dino Ignacio, se convirtió en un personaje de culto en Internet y ello también fue noticia en los medios tradicionales. La publicidad creció tanto que también lo hizo la preocupación de Ignacio quien desmanteló su sitio web y puso el siguiente mensaje: "Creo que esto se ha acercado demasiado a la realidad (...) Blas 
es malo". Su fantasía personal se convirtió en realidad. Lo que comenzó como broma en su web, se convirtió en noticia. Después, en crisis internacional y empresarial, reflejada tanto por los medios tradicionales como, sobre todo, virtuales. Posteriormente, el protagonista involuntario de la broma se ha transformado en personaje de culto $y_{1}$ desde 2003, en que se publicara el caso como "estudio científico" en la prestigiosa revista American Historial Review (Rosenzweig, 2003), en asunto científico de primera magnitud, publicado nuevamente con este otro enfoque en los medios de comunicación. Éste es el mundo de la cultura convergente, donde los esquemas tradicionales de comunicación como el modelo de Jakobson emisormensaje-receptor quedan radicalmente distorsionados. Un mundo donde la cultura de masas se convierte en alta cultura y la alta cultura (como los resultados científicos) en cultura de masas.

¿Qué posibilita este cambio de paradigma? En primer lugar, uno de los integrantes de la cultura convergente, la convergencia mediática (Jenkins, 2008: 14). Los circuitos que ha recorrido Blas son consecuencia de la globalización pero también de la convergencia y sinergias de los medios de comunicación. No obstante, el nuevo significado de convergencia, no se refiere tanto a convergencia de soportes mediáticos -tal y como era definido a principios de este siglo XXI- como, sobre todo, a un cambio cultural, liderado por la Red, en el que los consumidores mediáticos buscan otras informaciones, establecen nuevas conexiones entre contenidos mediáticos dispersos y los propios espectadores-usuarios-receptores-finales se convierten en emisores. Es decir, la convergencia no se produce en aparatos mediáticos, por muy sofisticada que sea su tecnología, sino en el cerebro de los emisores y receptores. La convergencia se produjo en el cerebro de Dino Ignacio.

El otro nuevo concepto necesario para comprender el paradigma de cultura convergente es el de "cultura participativa": opuesta al antiguo esquema de "espectador mediático pasivo". Ahora ya no puede hablarse de productores y consumidores mediáticos, como entes separados, que desempeñan funciones distintas. Todos somos ahora potenciales participantes activos.

El último término que me interesa exponer es el de "inteligencia colectiva" (Lévi, 1997). Este concepto parte de la premisa de que ninguno de nosotros puede saberlo todo. Especialmente en un mundo interconectado en el que existe más información de la que el cerebro humano puede abarcar. Sin embargo, cada uno de nosotros sabe algo y de algo, de forma que lo mejor es aprovechar las redes sociales cibernéticas (ahora más avanzadas con la Web 2.0) para construir un conocimiento en el que todos compartamos nuestras experiencias, juntemos las piezas y demos luz a una información nueva más exacta. Estas conversaciones en la red crean un "murmullo" cada vez más valorado en la industria mediática y que definirá su futuro en los próximos años.

Obviamente todos estos aspectos del nuevo paradigma pueden aplicarse a todo el arco de la comunicación, tanto la de masas como la de elite (la que hacen los expertos entre si). Pero apenas existen estudios. Algunos (muy pocos aún) interesantes en este campo provienen del mundo de la comunicación audiovisual donde, por ejemplo, analizan las intensas correspondencias, cada día más frecuentes, entre videojuegos y películas de cine: cómo unos se convierten en otros y viceversa. Otros enfoques abordan las interconexiones entre los guiones de las películas (o las series televisivas) y los clubes de fans agrupados en redes sociales en Internet quienes ahora presionan a los guionistas o elaboran tramas complementarias que propagan por la red.

\section{LA CULTURA CONVERGENTE APLICADA A LA COMUNICACIÓN CIENTÍFICA}

Sin embargo, en el ámbito de la comunicación científica apenas ha habido investigación sobre cómo le afecta este nuevo paradigma. La comunicación pública de la ciencia tiene dos fases: la comunicación entre científicos y, después, entre éstos y la opinión pública. Cualquier modificación en alguna de ellas modifica a la otra. En la primera fase ya comienzan a observarse algunos cambios muy interesantes que, obviamente, repercutirán en el periodismo científico. Veamos un ejemplo.

En enero de 2009 se celebró en la sede de la UNES$\mathrm{CO}$ en París un evento puntual: el congreso anual de la Unión Astronómica Internacional, una cita periódica de astrónomos y astrofísicos como cualquier otro congreso científico. El congreso se tituló "El papel de la astronomía 
en la sociedad y la cultura'", pero lo extraordinario, al margen de las ponencias en sí, fue que pudo detectarse cómo ahora coexisten varios canales de comunicación. El primero ha sido el habitual de la comunicación científica moderna, desde que se fundara la Royal Society en 1660: un grupo de científicos expone sus resultados a un público interesado. La ciencia moderna siempre ha sido definida como conocimiento público (Ziman, 1998). Pero las nuevas tecnologías posibilitaron que las ponencias fueran grabadas en televisión y emitidas por Internet donde, además, quedarán archivadas, aunque no se sabe por cuánto tiempo. (Se encargó de ello Web télé canalc2.tv, un canal cultural francés especializado en emitir coloquios y conferencias ${ }^{2}$.) En esa web, no sólo puede descargarse el vídeo de la conferencia, sino que también publica los materiales adicionales como la presentación de power point. De modo que no era necesario estar físicamente en París para asistir al congreso o informar de él en un medio de comunicación.

Otro factor revelador de las nuevas formas de comunicación fue que prácticamente la totalidad de los asistentes acudió con su portátil con conexión a Internet. Un grupo importante de ellos tenía sus propios blogs. De forma que iban retransmitiendo las ponencias (y sus impresiones sobre ponente y ponencia) en sus respectivos blogs en tiempo real. Al momento se generaban foros de discusión. Como había numerosos blogs, los participantes en los foros (de prácticamente todo el mundo: desde España o EEUU hasta Australia o Sudáfrica) podían rastrear los distintos blogs y comparar visiones y versiones. Esto último de buscar y rastrear informaciones similares es muy característico de la cultura convergente. En España, por ejemplo, uno de los participantes en el congreso, Javier Armentia, astrofísico y director del Planetario de Pamplona, realizó un seguimiento del congreso en su famoso blog de divulgación científica Por la boca muere el pez ${ }^{3}$. Pues bien, las discusiones suscitadas en los blogs pudieron ser transmitidas a los ponentes por los bloggers en el turno de preguntas $y_{\text {, }}$ a su vez, respondidas en el blog o transmitidas por televisión. Es decir, el ciudadano anónimo puede participar en el congreso científico de París desde su casa en Australia. Un segundo grupo de participantes tenía, además, un perfil en redes como Facebook, de forma que en ellas se dio la versión del congreso que querían escuchar los que compartían la red social. (Por ejemplo, si los y las ponentes estaban buenos/as físicamente.)
Los periodistas informaron de manera tradicional del congreso (acudiendo a la presentación en rueda de prensa) y, a su vez, reflejando lo que decian los blogs. La cobertura fue mundial. Algún medio (El Mundo, 16-01-2009), incluso, informó de la inauguración de una web específica (www. cosmicdiary.com). Algunos periodistas, como Dominique Leglu (diario Libération), fueron ponentes. Es decir, las fronteras habituales se diluyen. Muchos investigadores que no acudieron al congreso, pero que han visto las ponencias en los blogs se han podido bajar los vídeos por Internet. A los que sólo les ha interesado las referencias que citaban las ponencias, las han buscado directamente en los repositorios de las universidades y las revistas a través del Open Access. En algún caso se podía usar el hipertexto del power point de la presentación que aparecía en el canal de televisión para ir directamente a la referencia. Quien desconociera a los ponentes, ha podido rastrear su nombre en Internet y elaborarse un perfil. Bienvenidos a la nueva complejidad y potencialidades de la comunicación científica convergente.

El problema de toda esta metainformación que se generó en el congreso (y del propio congreso con sus sesiones grabadas y volcadas en la web) se resume, no obstante, en la duda de ¿qué quedará de todo esto dentro de 100 años? La Universidad de Cambridge, una de las más antiguas y prestigiosas del mundo, parece no fiarse mucho de la nueva era y publicará las actas de ese congreso en su editorial y como libro tradicional. Este último dato vuelve a reflejar la incertidumbre que, al menos por el momento, existe.

\section{LA FUENTE PERIOdÍSTICA SE TRANSFORMA EN MEDIO DE COMUNICACIÓN DE MASAS}

¿Cómo afecta todo esto al segundo eslabón: al periodismo científico? Pues creando distorsiones, incluso, en referentes que hasta ahora se tenían muy claros. Por ejemplo, uno de los pilares del antiguo periodismo era la fuente. "Un periodista vale lo que su agenda de fuentes", se solía afirmar. La fuente era quien declaraba (en el caso, por ejemplo, de la ciencia, era el investigador) y el periodista el encargado de transmitir esa declaración a la sociedad a través de los medios de comunicación de masas, eligiendo distintos géneros informativos según el soporte. El periodista se definía como alguien que trabajaba para una empresa con 
la capacidad de informar a una gran cantidad de audiencia. Pero, ahora, con Internet como soporte compartido, qué es la fuente y qué el medio de comunicación de masas.

En 2004 muchos científicos que se interesan por la geología, el clima o la geografía marciana estaban de enhorabuena: las sondas de la NASA Spirit y Opportunity se posaban en Marte para recoger valiosísimos datos científicos. Nada extraño se esperaba, ni se halló. Los estudiosos del periodismo científico, sin embargo, sí encontramos algo sorprendente: en las 24 horas que había durado el amartizaje del Spirit, la web de la NASA tuvo 225 millones de entradas. (Se contabiliza como entrada cada vez que un internauta accede a una página de la NASA, ya sea texto, foto, etc). En los 90 días que duró la misión, el número de visitas ascendió a 6.530 millones. Una cifra que rápidamente la NASA aclaró que suponía "más que la población total de la Tierra" que, en aquel año, alcanzaba los 6.300 millones. Un quinto de todo el tráfico procedía de fuera de EEUU $y$, a través de una encuesta, se determinó que un cuarto de los visitantes eran profesores o estudiantes de primaria o secundaria ${ }^{4}$.

Un estudio realizado en 2007 demostró que en mayo de ese año (un mes sin ninguna misión espectacular), las visitas únicas al portal de la NASA fueron de 3.952 .000 de personas. Sin embargo, las visitas únicas a portales de ciencia y tecnología de medios de comunicación tradicionales eran muy inferiores. Sólo la CNN alcanzaba los 502.000 visitas. Es decir, casi ocho veces menos. La del portal científico de la FOX o la CBS no podía cuantificarse porque no llegaban al mínimo para ello que se establecía en 360.000 visitas. Sólo un portal web, Space.com (que no tiene nada que ver con los medios tradicionales) se acercaba a la NASA con sus 1.178 .000 visitas únicas. Otro dato muy interesante fue que mientras que la permanencia media en el portal de la NASA fue de 12:33 minutos, en el de la CNN sólo fue de 2:38 minutos (cinco veces menos tiempo). (Hedman, 2007.)

¿Por tanto, qué es la NASA: una fuente para los medios o un medio de comunicación en sí mismo? Posiblemente ambas cosas, pero claramente es también un medio de comunicación con una audiencia superior a la CNN (sección de ciencia) o la CBS o FOX. La NASA es conciente de ello y mantiene dos vías de comunicación: una con los periodistas (la tradicional de las fuentes, aunque también ha variado) y otra directamente con la sociedad. Potencia su imagen de marca $(E d o, 2001)$ en ambos sentidos.

La vía de comunicación con los periodistas se ha enriquecido, en el sentido de que ahora todo periodista de cualquier sitio del mundo, independientemente del medio en el que esté, puede suscribirse al servicio de noticias de la NASA. Le llegarán puntualmente por el correo electrónico las últimas novedades de las misiones espaciales, comunicados sobre hallazgos científicos o videos con declaraciones y ruedas de prensa de los científicos de la agencia espacial. Es decir, no depende de los grandes medios de comunicación (agencias de noticias, cadenas internacionales de televisión, etc.) porque todos tienen la misma información.

Pero la gran novedad es que eso le llega también al conjunto de la sociedad de forma directa, sin necesidad de un intermediario periodista. El ciudadano anónimo interesado puede acceder a la web de la NASA donde puede encontrar todos esos contenidos que, prácticamente, copia el periodista. Pero es que, además, cualquier ciudadano puede suscribirse al servicio de noticias de la NASA, porque la tecnología lo permite, en igualdad de condiciones que un periodista. Antes era físicamente imposible, pero ahora no. El ciudadano con espíritu divulgativo -0 vengativo, o el que sea- puede comentar las noticias de la NASA en su blog, copiar las imágenes, colgar el vídeo de las ruedas de prensa o de los astronautas en la Estación Espacial Internacional (ISS).

Los realmente interesados en información espacial respetan más a estos bloggers que a los periodistas. Javier Armentia, por ejemplo, que es astrofísico y comunicador tiene gran predicamento en la web. Mucho más que los periodistas científicos en activo en medios tradicionales. Por tanto, estos bloggers tienen mucho poder y posibilidades de crear "murmullo mediático-cibernético" que, a su vez, pueda influir en las decisiones de la NASA. El caso del murmullo producido por la destitución de James $E$. Hansen, jefe del servicio del Departamento Atmosférico del Instituto Goddard de la NASA, es paradigmático. En el murmullo cibernético apareció que la Administración Bush le había prohibido impartir conferencias donde avalara el calentamiento global. Del murmullo cibernético pasó a The New York Times (29-01-2006) y, de ahí, nuevamente a la red, reconsiderando la NASA su decisión. Otro caso muy interesante que no podemos abordar aquí en profundidad 
es el del murmullo que se está creando en la red para que Plutón vuelva a ser declarado planeta.

Pero hay otra vuelta de tuerca: la NASA emite fragmentos cada vez mayores de la vida diaria de los tripulantes de la Estación Espacial Internacional. Sin duda, uno de los hitos científicos más importantes de la ciencia actual e, incluso, de la historia humana, pues en su filosofía subyace la idea de que sea una ciudad de investigación en la que, a partir de su fundación (en 2001), siempre haya humanos. Es decir, que siempre existan humanos fuera del planeta Tierra. Nada más y nada menos. La Estación es muy importante desde el punto de vista científico y cultural y, por ello, todos los periodistas tienen acceso a la web que transmite fragmentos de la vida de los tripulantes en directo. Pero también cualquier ciudadano puede adentrarse como si fuera un reality show. ¿Qué diferencia la transmisión de la vida de los tripulantes de la ISS en directo del programa Gran Hermano? De nuevo una mezcla de cultura de masas y alta cultura convergiendo.

Una crítica procedente de las facultades de periodismo, que observan con preocupación que su misión de formación de periodistas se desvanece en el nuevo orden, es que "siempre se necesitarán periodistas porque, aunque sea en la NASA, alguien tiene que escribir los reportajes". Es cierto, pero en primer lugar la NASA no tiene a periodistas, sino a licenciados en ciencias con habilidades comunicadoras (algo similar a lo que ocurre en Nature); que es algo muy diferente al concepto tradicional de periodista. Estos comunicadores (que escriben hasta reportajes para la web de la NASA) hacen ahora de fuente (porque sus reportajes son literalmente copiados en todos los medios del mundo) y las fuentes - los científicos de la NASA- hacen de periodistas comentando las noticias en sus blogs, algunos de ellos muy seguidos. Al margen de los que cada científico pueda tener, hay uno (www.opennasa. com) en el que los científicos hablan de sus problemas internos, pero es de acceso público. Su intención es crear "murmullo mediático".

La NASA cuida muy bien a los medios tradicionales dándoles mucha información, pero ha captado perfectamente que ella es en sí misma un medio de comunicación de masas (con imagen de marca), creando enlaces en su web para los padres, los profesores, los niños, etc. Es decir, la fuente habla directamente con la sociedad. Esta filosofía (importada poco a poco en España principalmente por el CSIC o el IAC) está comenzando a dar frutos muy interesantes. Ante la crítica de que fuentes como la NASA -0 el CSIC en España- son dependientes del gobierno, otras instituciones científicas independientes están copiando la política y se están convirtiendo en medios de comunicación de masas. Las más relevantes son la Royal Society inglesa y la Asociación Americana para el Avance de la Ciencia. Ellas mismas se han convertido en medios de comunicación con webs visitadas por millones de usuarios en busca de noticias o documentos sobre cambio climático, darwinismo o cualquier asunto científico. Sus responsables están empezando a controlar cómo dominar el "murmullo mediático cibernético". Lo más curioso es que al convertirse estas fuentes en medios de comunicación de masas, han potenciado su imagen de marca (y su impacto mediático) y ahora son mucho más citadas como fuentes por los medios tradicionales, que cada día se hacen más eco de los murmullos cibernéticos.

\section{LA DictaduRA dE LA AUdIENCIA: LA CIENCIA NACE PARA SER NOTICIA}

Cuando una fuente (en este caso científica) se convierte en medio de comunicación, empieza a pensar en términos periodísticos, no científicos. ¿Qué produce, entonces, esta fuente: ciencia que luego sale en los medios, ciencia diseñada para salir en los medios o noticias a las que le coloca un respaldo científico? Veamos esta nueva desnaturalización de viejos conceptos -como que "periodismo es distinto a ciencia"- con otra de las fuentes hegemónicas en periodismo científico: las revistas Science y Nature y la denominada "ciencia diseñada para salir en los medios" (Elías, 2002: 123-137).

Science y, sobre todo, Nature tienen una politica de comunicación tan sofisticada y adaptada a Internet que ambas se han convertido en nuevos medios de comunicación, pero con una particularidad: como están disfrazados de fuentes, pueden imponer su agenda sobre el resto de los medios del mundo sin que parezca que imponen línea editorial. Todos los jueves la mayoría de los periódicos del mundo (y esto es literal) incluyen alguna noticia de Nature y los viernes de Science, dias en los que respectivamente cada una sale al mercado. Este alcance global es posible porque con la

ARBOR CLXXXV 737 mayo-junio [2009] 623-634 ISSN: 0210-1963

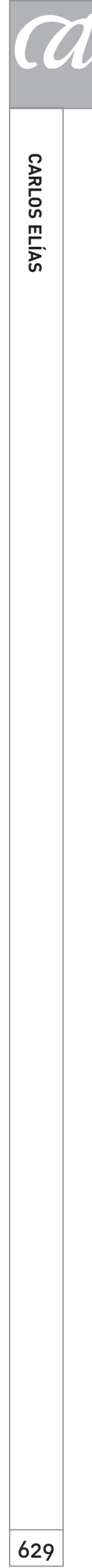


nueva cultura de la Red, cada una de ellas envía sus comunicados a una media de 4.000 periodistas. En 2007 ambas publicaciones recibieron el Premio Príncipe de Asturias de la Comunicación y Humanidades. Su candidatura ganó, por ejemplo, a la de la agencia fotográfica Magnum o a la mismísima BBC. Sólo este detalle delata su gran poder como medio de comunicación de masas.

En los comunicados de prensa que envían estas revistas está prácticamente todo elaborado. Los reportajes de prensa están completamente redactados. Los cortes y las imágenes para televisión están ya editados. Todo son facilidades para que quien no tiene ni idea de ciencia pueda informar sobre ella. El periodista de los medios tradicionales sólo tiene que "copiar y pegar". Es decir, el verdadero periodismo científico se hace ahora en estas revistas (en las fuentes), no en los medios.

Esta relación, así como la sumisión de los medios a los comunicados de prensa de Nature o Science es tal que, según un estudio, sólo tienen posibilidades de ser mencionados por la prensa aquellos artículos seleccionados para los comunicados de prensa de estas revistas (De Semir et al., 1998). Es decir, ningún periodista se lee la revista. Además, el orden en el que aparecen las investigaciones en dichos comunicados también influye decisivamente en su difusión en la prensa. Así, los artículos que figuran en primera o segunda posición en el comunicado de prensa, son los que alcanzan una mayor difusión en los periódicos. Es decir, el periodista de medios tradicionales no es capaz de valorar y jerarquizar información por sí mismo. Ha perdido (o delegado en la fuente) esa capacidad.

¿Por qué estas revistas están tan interesadas en convertirse en medios de comunicación? La respuesta nos revela cómo son ahora las relaciones medios-fuentes. En primer lugar, debe aclararse que los científicos y su actividad no son valorados en función de criterios estrictamente científicos, sino más bien en términos de audiencias. Porque esto es $-\mathrm{y}$ no otra cosa- la definición del Science Citation Index. No es una cuantificación de la excelencia de la ciencia, sino de cuánta gente (audiencia) te cita. Cuanto más lo hagan, más aumenta el índice de citación de la revista donde el científico ha publicado, por lo tanto, según los nuevos parámetros científicos-mediáticos, esa revista y el científico que publica en ella tendrán más prestigio.
Uno de los resultados más interesantes dentro del campo de la comunicación de la ciencia es la demostración empírica de que el índice de impacto puede mejorarse si los artículos son publicados en la prensa. Es decir, existe una relación directa entre que la ciencia sea calificada como "excelente" -pues es muy citada- y la posibilidad de que sea divulgada en los medios de comunicación de masas. Esta circunstancia fue demostrada en un estudio publicado en New England Journal of Medicine y en el cual sus autores analizaron los artículos de la citada revista publicados en 1978 y 1979 (Phillips et al., 1991). Compararon los que aparecieron en The New York Times con los que no lo hicieron y detectaron que los estudios que se habian publicado en el periódico estadounidense habían sido citados un $72,8 \%$ más en el año siguiente a su publicación que los que no aparecieron en ese diario.

Lo más relevante es que la diferencia significativa de citas persistió durante al menos 10 años tras la publicación de los resultados científicos en el periódico. Es decir, a los científicos les interesa que sus resultados salgan en los medios de comunicación porque ello implica mayor índice de citación y, por tanto, mayor prestigio, según los actuales baremos de evaluación de la actividad científica.

Si esto se estableció para 1978, cuando no existía Internet y cuando el científico debía ir a la biblioteca a buscar el artículo en papel, imagine el lector el efecto multiplicador de este fenómeno en una era como la actual en la que el hipertexto te puede llevar directamente de la noticia periodística al artículo científico base y en la que las políticas de Open Access y repositorios de revistas e instituciones científicas te permiten acceder al artículo original inmediatamente.

Los gabinetes de prensa de estas revistas van creando durante la semana anterior a la publicación (los comunicados se envían embargados a los periodistas con una semana de antelación) un murmullo mediático con correos de refuerzo para asegurarse de que el periodista elige la noticia. Por otra parte, los criterios de selección de los artículos científicos son periodísticos porque al aumentar la posible cobertura se incrementa el factor de impacto (Elías, 2008: 329). Es decir, se impone la dictadura de la audiencia. Esto afecta, por ejemplo, a cuándo se publica el artículo científico (se hace coincidir con efemérides periodisticas). Ello puede rastrearse desde fechas tan tempranas 
como 1996, cuando el 4 de enero (antevíspera de Reyes) Nature publica un artículo sobre el efecto analgésico de la mirra (Dolara, 1996), con el titular "¿Por qué los tres Reyes Magos llevaban mirra?" Pero la estrategia es cada día más común. El mismo dia en que revisaba este artículo (jueves 12-02-2009) Nature publicó una investigación sobre "las diferencias genéticas entre el hombre y el chimpancé" (Marques-Bonet et al., 2008). El titular del press release de Nature señalaba "Hombre y mono, parientes no tan cercanos". Casualmente ese día se cumplía el 200 aniversario del nacimiento de Darwin y la noticia fue mundial. Quienes quisieron arremeter contra Darwin, ya tenían argumento. La NASA también usa mucho esta política mediática. Los cálculos para la llegada de la sonda espacial NEAR a la superficie del asteroide Eros (nombre del dios griego del amor) no se elaboraron en función de variables científicas, sino periodísticas: tenía que posarse el 13-02-2001, para que saliera en toda la prensa mundial el día siguiente (14 de febrero) día de los enamorados. Alta cultura (la ciencia de los asteroides) convertida en cultura de masas de lo más chabacano.

\section{De la dictadura de la audiencia a la CIENCia SENSACIONALISTA O "CIENCIA AMARILLA"}

El problema de querer parecerse a un medio de comunicación, y acatar la dictadura de la audiencia, es que, a veces, se cae en el sensacionalismo. Ya Hearst y Pullitzer comprobaron desde finales del XIX y comienzos del XX cómo el sensacionalismo es una palanca de atracción de audiencia. ¿Pueden las revistas científicas seleccionar "ciencia amarilla" para que sea más publicada por lo medios $y_{\text {, por }}$ tanto, aumentar su factor de impacto como revista? En 2003 Nature publicaba un estudio con la siguiente conclusión: "La mayoría prefiere besar hacia la derecha". Esa era la conclusión del gabinete de prensa de Nature, porque el artículo, que en realidad sólo entraba en la categoría de "comunicación breve", se titulaba: "Comportamiento humano: la persistencia en los adultos de la asimetría al girar la cabeza (Güntürkün, 2003)". Es decir, el sensacionalismo procede ahora de la fuente, porque usa criterios periodísticos. La metodología de investigación, citada en el propio artículo científico y en el comunicado, hablaba de que el investigador había observado "cómo se besaban las parejas en los lugares públicos (aeropuertos, estaciones de tren, playas y parques) en los Estados Unidos, Alemania y Turquía". Esto es terrible porque la imagen que el propio científico ofrece a la sociedad es la de que realmente él es un mirón que reviste su patología de ciencia. Justo el arquetipo de científico chiflado y carente de afectos que transmite el cine. La percepción proyectada a un jovencito -y no tan joven que escucha la noticia- es la de que "la gente de verdad, besa de verdad y los científicos sólo están para mirar cómo besan otros, no para besar ellos. Con eso se conforman". Todo esto, en el mejor de los casos. En el peor se equipara a un científico con un trastornado sexual. Y eso, reitero, se está haciendo desde la fuente (Nature), no desde el periodista. Es decir, eligen clichés periodísticos.

Esa investigación se prefirió desde el gabinete de prensa de Nature (y se impuso en todos los medios del mundo) sobre otras del mismo número (el 421) que tenian un mayor interés científico como estudios sobre autoinmunidad, sobre gravedad cuántica, un análisis sobre los movimientos de las proteínas en las células, el origen de los carnívoros en Madagascar, el papel de la interleukina-23 en la inflamación del cerebro o los efectos en los sedimentos coralinos de la Gran Barrera australiana tras la colonización europea. Normalmente en un periódico o informativo sólo hay espacio para una noticia de ciencia al día, por lo que la que consiguió ese espacio fue la de "besar a la derecha". Y, posiblemente, su investigador también tendrá más citas durante los 10 años siguientes y logrará más dinero en proyectos competitivos. Esto es un efecto perverso para la ciencia cuyo origen está en la aplicación de la cultura mediática a la producción científica (Elías, 2008:329).

Este efecto ha crecido de forma exponencial no sólo por la cada día mayor importancia del $\mathrm{SCl}$, sino por la cultura de la Web 2.0. Si esta política la sigue Nature, las revistas de segundo nivel son aún más agresivas. Pero lo interesante ahora, dentro de este patrón de cultura convergente, es que son los medios de comunicación los que denuncian esta "ciencia amarilla" proveniente de fuentes en teoría solventes. Este último mes de enero de 2009 ha habido dos casos que lo ilustran. El primero fue una investigación publicada en la respetable Journal of Evolution and Human Behaviour que, en su número 30, publicaba un estudio que relacionaba un mayor y mejor orgasmo en las mujeres con el hecho de que sus parejas fueran muy solventes económicamente (Pollet y Nettle, 2009). El titular-idea 
que más apareció en los medios fue "La ciencia demuestra que el tamaño sí importa... pero el de la cuenta corriente". Inmediatamente se desataron foros en Internet criticando el método científico de ese estudio. No sólo grupos feministas, sino partidos políticos y organizaciones sociales hablaron de "sensacionalismo científico". El portal de la versión electrónica de The Times se colapsó cuando tituló "Wealthy men give women more orgasms". La repercusión ha sido tal, que un medio tradicional [El Mundo (Magazine), 15-02-2009: 45], bajo el título de "Los ricos las hacen gozar más", hablaba ya de "ciencia amarilla".

Ese mismo periódico tuvo durante cuatro días ([7-10]-022009) como noticia más leída una procedente de un blog ${ }^{5}$ (insertado en elmundo.es), pero no de un periodista; sino de un urólogo, Juan Ignacio Martínez Salamanca. En su blog criticaba los resultados científicos publicados en la British Journal of Urology International, según los cuales se demostraba una supuesta relación entre "alta frecuencia de masturbación y cáncer de próstata (Dimitropoulou et al, 2009)". El editor de salud del diario El Mundo, José Luis de la Serna, se hacía eco en su columna semanal de la gran repercusión del blog y calificaba el estudio de "pseudociencia". (Suplemento Salud: 12-02-2009.) No obstante, el que fuera un asunto sensacionalista ayudó a El Mundo a tener más audiencia. ¿Dónde está el sensacionalismo, en los medios o en las fuentes? En la cultura convergente la información es un bucle y ello la hace mucho más atractiva.

\section{Conclusión}

La conclusión a cómo se modifica la comunicación científica en la era de la filosofía web 2.0 con la aplicación del paradigma de la cultura convergente está clara: ya nada es lo que era ni lo que parece. Ello no es necesariamente bueno ni malo. Desde el punto de vista de la ciencia de la información, los matices son ahora mucho más ricos y las posibilidades de investigación de nuevos campos están mucho más abiertas.

Sin embargo, desde el punto de vista de la profesión periodística, me temo que el ciberperiodismo prefiere a los bloggers frente los periodistas tradicionales. Desde 2001, en el II congreso de Periodismo Digital ya se señaló que "ha habido un notable retroceso de las condiciones laborales, porque cada vez menos personas hacen una cantidad mayor de trabajo que, además, incluye actividades como marcar, copiar, pegar, empaquetar o duplicar distintos tipos de archivos publicables, que no pueden identificarse como actividades periodísticas (Edo, 2001: 59)".

La gran ventaja que siempre han tenido los periodistas frente al ciudadano común es el acceso directo a las fuentes. Pero ahora ese acceso es compartido con la sociedad. Y nada demuestra que un blog identificado de un profesor universitario o de un científico del CSIC o la NASA no ofrezca una información y análisis más interesante que el que procede del periodista. "Los weblogs quedan fuera del entramado político-mediático-empresarial de los diarios digitales, muchos internautas se convierten en testigos directos de la realidad informativa" (Franco Álvarez, 2005: 181).

De hecho, en el periodismo bélico se ha demostrado -por ejemplo, en la invasión de Iraq (2003)- que la mejor información procedia de un blog de un joven iraquí llamado "Salam Pax (paz en árabe y en latín)". La filosofía web 2.0 ayudó a que su éxito fuera tan grande que Google, el proveedor del blog, tuvo que replicarlo para que no colapsara. El blog también se convirtió en noticia en los medios tradicionales (ABC 2-04-2003). Su información era mucho mejor que la de los periodistas apoltronados $-\mathrm{y}$ vigilados- en el Hotel Palestina. En la última campaña electoral estadounidense hemos visto la apoteosis de toda esta nueva cultura convergente aplicada a la política. En cualquier caso, lo mejor es que estamos viviendo un período de transición hacia algo que, con toda seguridad, en nada se parecerá a lo que vivimos ahora. 
1 Symposium 260 International Astronomical Union, "The role of Astronomy in Society and Culture" (París, Francia, 19-23 enero), www.iaus260. obspm.fr.

2 El congreso puede verse en la siguiente dirección: http://www.canalc2.tv/video.asp?idvideo $=8428$.

3 http://javarm.blogalia.com//historias/61603. En este link aparece además, alguna historia sobre el congreso de la IAU en París.

4 Información ofrecida en rueda de prensa por NASA y analizada, entre otros medios, en el portal educativo http://www.distance-educator.com/. Cuantificación realizada por Nielsen/ Netratings.

5 Blog Salud Sexual:http://www.elmundo.es/elmundosalud/2009/02/05/saludsexual/1233822489.html.

\section{BIBLIOGRAFÍA}

Canga Larequi, Jesús (2001): "Periodismo e Internet: nuevo medio, vieja profesión", Estudios sobre el mensaje periodístico, 7, 33-48.

De Semir, V.; Ribas, C. y Revuelta, G. (1998): "Press Releases of Science Journal Articles and Subsecuent Newspaper Stories on the Same Topic", JAMA 280, 294-5.

Dimitropoulou, Polyxeni et al. (2009): "Sexual activity and préstate cancer risk in men diagnosed at a younger age", BJU International, 103 (2), 178185.

Dolara, Piero et al. (1996): "Analgesisc effects of myrrh", Nature, 397, 29-29.

Recibido: 9 de febrero de 2009 Aceptado: 23 de febrero de 2009
Elías, Carlos (2002): "Influencia de las revistas de impacto en el periodismo científico y en la ciencia actual" Revista Española de Investigaciones Sociológicas, 98, 123-196.

Elías, Carlos (2008): La razón estrangulada. La crisis de la ciencia en la sociedad contemporánea, Debate, Barcelona.

Franco Álvarez, Guillermina (2005): "Una nueva forma de hacer periodismo gratuito: el weblog impreso QuéMadrid", Ámbitos, Revista Internacional de Comunicación, 13-14, 177-184.

Güntürkün, Onur (2003): "Human behaviour: adult persistence of head-turning asymmetry", Nature, 421, 711-711.

Hedman, Eric (2007): "The fragility and resilience of NASA", The Space Revew (http://www.thespacereview.com/article/924/1)

Jenkins, Henry (2006): Convergence culture, New York Univerity Press, Nueva York (en 2008 ha salido la versión en español en Paidós).

Lévi, Pierre (1997): Collective Intelligence: Mankind's Emerging world in Cyberspace, Perseus Book, Cambridge.

Lozano, Jorge (2008): "Cultura de masas/ Cultura alta: ¿Convergencia o transducción?", conferencia en Congreso Septenio Canarias (recogida en www. septenio.es), La Palma.

Phillips, P. D.; Kanter, E.; Bednarczyk, B. y Tastad, P. (1991): "Importance of the lay press in the transmission of medical knowledge to the scientific community", The New England Journal of Medicine, 325, 1180-1183.

Pollet, Thomas V. y Nettle, Daniel (2009): "Parter wealth predicts self-reported orgasm frequently in a sample of Chinese women", Journal of Evolution and Human Behavior, 30 (2), 146-151.

Marques-Bonet, Tomas et al. (2008): "A burst of segmental duplications in the genome of the African great ape 
ancestor", Nature Genetics, 457, 877881 (Letter).

Rosenzweig, R. (2003): "Scarcity or Abundance? Preserving the Past in a Digi- tal Era", American Historical Review, 108.

Toffler, Alvin (1980): La tercera ola, Plaza y Janés, Barcelona.
Ziman, John (1998): Real Science: what it is, and what it means, Cambridge University Press, Cambridge. 